\title{
Handedness, hemispheric asymmetries, and joke comprehension
}

\author{
Seana Coulson*, Christopher Lovett \\ Cognitive Science Department, 0515, University of California, San Diego, 9500 Gilman Drive, La Jolla, CA 92093-0515, USA
}

Accepted 12 November 2003

\begin{abstract}
To address the impact of differences in language lateralization on joke comprehension, event-related brain potentials (ERPs) were recorded as 16 left- and 16 right-handed adults read one-line jokes and non-funny control stimuli ("A replacement player hit a home run with my girl/ball,"). In right-handers, jokes elicited a late positivity 500-900 ms post-stimulus onset that was largest over right hemisphere (RH) centro-parietal electrode sites, and a slow sustained negativity over anterior left lateral sites. In left-handers, jokes elicited a late positivity 500-900 ms post-onset that was larger and more broadly distributed than in the right-handers' ERPs. In right-handed women, the late positivity was larger over RH electrode sites. In left-handed women, the late positivity was bilaterally symmetric. The highly asymmetric slow sustained negativity over left anterior electrode sites was absent from left-handers' ERPs to jokes. Differences may reflect more efficient inter-hemispheric communication in the left-handers, as they are reputed to have relatively larger corpus callosal areas than right-handers. Results support the portrait of more bilateral language representation among left-handers, and suggest language lateralization affects highlevel language comprehension tasks such as joke comprehension.
\end{abstract}

(C) 2004 Elsevier B.V. All rights reserved.

Theme: Neural basis of behavior

Topic: Cognition

Keywords: Language; Lateralization; Jokes; ERP; Handedness; Hemispheric asymmetry

\section{Introduction}

One of the most intriguing findings in the study of brain function is the thesis that the two cerebral hemispheres, though anatomically very similar, display different functional specializations - especially with respect to language production and comprehension. The most dramatic evidence of the asymmetry of the linguistic capacities of the left and right cerebral hemispheres comes from the study of brain-damaged patients. Broca [6] reported two patients who experienced profound communicative deficits following large left frontal lobe lesions. Similarly, Wernicke [73] reported two patients with severe language comprehension deficits, apparently due to the presence of a lesion in the posterior superior temporal gyrus of the left hemisphere. In contrast, the incidence of aphasic deficits in patients with lesions to the right hemisphere (RH) is far less common [31].

Language deficits have also been associated with damage to the right hemisphere. But while patients with left hemi-

\footnotetext{
* Corresponding author. Tel.: +1-858-822-4037; fax: +1-858-534-1128

E-mail address: coulson@cogsci.ucsd.edu (S. Coulson).
}

sphere damage (LHD) often present with severe difficulties in basic aspects of language production and comprehension, patients with RHD exhibit more subtle deficits involving the relationship between an utterance and its context. RHD production, for example, is marked by socially inappropriate remarks, tangential speech, digressions of topic, combined with a failure to utilize nonverbal cues [40]. In experimental studies of their comprehension, RHD patients have been shown to exhibit a variety of pragmatic deficits. These include difficulty drawing inferences necessary to understand certain kinds of jokes [7], overly literal interpretation of metaphoric language [74], and difficulty interpreting sarcastic utterances $[53,54]$.

\subsection{Handedness and hemispheric asymmetry for language}

Note that the above statements about typical patterns of hemispheric asymmetry for language presuppose that the patients are right-handed (right-handers constituting $90 \%$ of the population). Since Broca's discovery that language deficits in right-handed people are typically associated with damage to the left, but not right cerebral hemisphere, 
neuropsychologists have been fascinated by the relationship between language lateralization, handedness, and the various genetic factors that influence cerebral asymmetry in the normal population. Presumably, because Broca's original two patients were right-handed, he assumed that language lateralization would be reversed among left-handers. However, subsequent research has revealed that the majority of left-handers are left dominant for language, but that lefthanders are more likely than right-handers to display "atypical"- that is, either bilateral or right hemisphere-language dominance.

Indeed, a number of factors suggest handedness is relevant to hemispheric asymmetry for language capacity, and support the thesis that language lateralization is less extreme among left-handers. Behavioral tests of hemispheric specialization, such as dichotic listening and tapping interference paradigms, indicate that lateralization of language functions is less extreme among left-handers than their right-handed counterparts (see Ref. [5] for a review). On the dichotic listening task, for instance, the right ear advantage for accuracy has been found to correlate with handedness [10]. Lishman [51] reports that the incidence of a right ear advantage on the dichotic listening task is largest among right-handers, intermediate among mixed handers, and least frequent among left-handers. Further, ear difference scores were significantly smaller among left-handers with a family history of sinistrality [51].

Unfortunately, behavioral tests of asymmetry in normal adults have yielded inconsistent results. Several studies testing large numbers of individuals (viz. 100-200) on the dichotic listening task failed to find reliable effects of handedness [49,67], though Lake and Bryden did detect an effect of sex (with males being more lateralized). Other studies report effects of handedness, but not sex or familial sinistrality on very similar tasks $[58,61]$. Conflicting results may stem from the fact that the observation of a right ear advantage among right-handers and a left ear advantage among left-handers depends on the presence of a strong hand preference $[20,46]$, and that sex $[50,55]$ and familial sinistrality [28] also affect language lateralization, and that both of these variables may interact with handedness.

Like evidence from behavioral asymmetries in auditory verbal processing, tests of visual language processing using the divided visual half-field reveal similarly mixed results. Some studies report a right visual field (left hemisphere) advantage among both left- and right-handers [9,36,57]. Others report that left-handers with a history of familial sinistrality are more likely display either a left visual field (right hemisphere) advantage, or at least the absence of a right visual field advantage [56,78]. However, there is at least one report that left-handers with a history of familial sinistrality are more likely to display right visual field (left hemisphere) advantage than are left-handers without a history of familial sinistrality [35].

Historically, the intracarotid amobarbital procedure, or Wada test, has been used to assess language lateralization in right and left-handers by measuring the incidence of speech arrest after the administration of amobarbital to the patient's left and right hemispheres, respectively. Results of the Wada test indicate that between $92 \%$ and $99 \%$ of right-handers are left hemisphere dominant for language (see Ref. [52] for a review). Among left-handers without any early brain injury, $85 \%$ are left hemisphere dominant, while $15 \%$ were either right hemisphere dominant, or had bilateral language representation [64]. However, extension of these results to the general population has always been tenuous, as the Wada test has almost exclusively been administered to patients with intractable epilepsy as part of their pre-surgical workup.

More recently, the relationship between handedness and language lateralization has been examined in normal, healthy adults with various neuroimaging technologies. Pujol et al. [63] assessed language lateralization in normal adults by comparing functional magnetic resonance imaging (fMRI) activation of the lateral frontal lobe in a language task. Operationalized as the hemisphere with the greater number of voxels activated, Pujol et al. found that lefthanders were indeed more likely to display atypical language dominance. Among right-handers, 96\% showed left lateralized activation, while $4 \%$ showed right lateralized activation. Among left-handers, $76 \%$ were left lateralized, $10 \%$ were right lateralized, and $14 \%$ had bilateral activation.

Similarly, Szaflarski et al. [70] assessed degree of lateralization in healthy adults by measuring the extent of fMRI (BOLD) activation on a language task in lateral, medial, frontal, and temporal regions of interest. A lateralization index (LI), obtained by computing the ratio of voxels activated in the left and right hemispheres, correlated with participants' handedness quotients as assessed via the Edinburgh Inventory [60]. More focused analyses revealed that participants' handedness quotients significantly correlated with frontal LI, but not with the temporal or medial LI, suggesting handedness is more closely linked to lateralization of frontal language areas than to other brain regions.

Comparable results have been obtained using repetitive transcranial magnetic stimulation (rTMS) to assess the functional relationship between handedness and language lateralization, by recording the percentage of left- and righthanders in which rTMS resulted in a disruption of naming ability. Among right-handers, speech arrest occurred with left hemisphere stimulation in $87.5 \%$ of the subjects, with right hemisphere stimulation in $4.2 \%$ of the subjects, and with stimulation of either hemisphere in $8.2 \%$. Among lefthanders, $73.7 \%$ were left hemisphere dominant, $10.5 \%$ were right hemisphere dominant, and $15.8 \%$ had bilateral language representation. Among mixed handers, 57\% had bilateral language representation and $43 \%$ were left hemisphere dominant.

Other studies indicate a relationship between the degree of handedness and the degree of language lateralization. Knecht et al. [43] found a near linear relationship between the degree of handedness, as assessed via the Edinburgh Inventory, and language lateralization as assessed via func- 
tional transcranial Doppler sonography (fTCD) during a word generation task. Although left handedness is neither necessary nor sufficient for right hemisphere language dominance, Knecht et al. clearly demonstrate that right hemisphere dominance is more likely among left-handers and among those who have at least one left-handed parent. Moreover, Knecht et al. [44] have shown that language lateralization as indicated by fTCD during a word generation task predicted language deficits induced by rTMS to posterior language regions. Taken together, these studies suggest that one's degree of handedness is associated with differences in the cerebral organization of language related to one's ability to compensate for rTMS to putative language regions.

Research with rTMS is thus concordant with the observation in aphasiology that left-handers and right-handers with a history of familial sinistrality are less likely to experience language deficits after a stroke affecting the left hemisphere. Early studies by Benton [3] revealed that while $60 \%$ of righthanders with left hemisphere lesions presented with language impairments, only $32 \%$ of left-handers did. Hecaen and Sauget [32] report that though left-handers with left hemisphere lesions typically experience similar production difficulties as do right-handers, they are less likely to present with comprehension deficits. Interestingly, only left-handers experience agraphia and alexia as a result of right hemisphere lesions [25]. Further, left hemisphere lesions in left-handers occasionally result in spatial disorientation, a deficit typically associated with right hemisphere lesions [29].

\subsection{Handedness and "right hemisphere" language processes}

Studies of the relationship between handedness and hemispheric asymmetry thus suggest that left-handers are less lateralized for language than right-handers, and potentially less lateralized for visuo-spatial processing, a set of processes typically lateralized to the right hemisphere [34]. One issue raised by these findings is how the decreased hemispheric asymmetry in left-handers affects language comprehension tasks that rely differentially on one hemisphere. Although many researchers have explored the impact of handedness on fundamental language processes such as speech production and word comprehension $[30,32,33,69]$, few studies have addressed whether high level language processing differs as a function of handedness (but see Ref. [71]). In particular, the consequences of varying degrees of hemispheric asymmetry for joke comprehension presents itself as an important topic worthy of study.

Jokes presuppose the speaker's ability to interpret language against background knowledge - a language comprehension process typically associated with right hemisphere function. In the following joke, "I let my accountant do my taxes because it saves time: last spring it saved me ten years," the reader begins by constructing a mental model in which a busy professional pays an accountant to do his taxes. However, at "years" she is forced to go back and reinterpret "time" to evoke a frame where a crooked businessman pays an accountant to conceal his illegal business dealings.

Coulson [14] has called this sort of conceptual revision frame-shifting, and suggests it reflects the operations of a semantic reanalysis process that reorganizes existing information into a new frame or schema retrieved from long-term memory. In the example above, frame-shifting involves mapping the information contained in the original busyprofessional interpretation into the crooked businessman frame. Jokes such as this one violate normal expectations, and in so doing, highlight normal dependency on background knowledge to structure expectations and enrich our interpretation of language.

Difficulty understanding jokes has long been associated with right hemisphere damage $[4,7,24]$, especially damage to the right frontal lobe [68]. In fact, research suggests the joke comprehension deficits associated with right hemisphere damaged patients involves the conceptual demands of frame-shifting, as RHD patients have also been shown to have trouble interpreting nonjoke materials that require semantic reanalysis [8]. Moreover, a neuroimaging study of healthy adults indicated that joke comprehension elicits increased RH activity [26].

Various electrophysiological indices of joke comprehension have been reported by Coulson and Kutas [16], who recorded event-related brain potentials (ERPs) from adults reading either one-line jokes or non-joke controls with equally unexpected endings. Joke and non-joke ERPs differed depending on participants' ability to understand the joke. In people who got most of the jokes, Coulson and Kutas observed a left-lateralized sustained negativity (500$900 \mathrm{~ms}$ ), indexing frame-shifting, as well as an N400 and later posterior positivity [16]. People whose comprehension was poor showed only a right frontal negativity (300-700 $\mathrm{ms})$ to jokes.

Although Coulson and Kutas' findings do not report direct evidence for RH participation in joke comprehension, a number of the ERP effects associated with getting jokes were lateralized, suggesting that the contributions of one hemisphere were more important than those of the other [16]. The late positivity was larger over right than left hemisphere scalp sites. Further, the sustained negativity 500-900 ms was observed at only a few left anterior scalp sites, and was not evident over comparable right hemisphere sites. The sustained anterior negativity reported by Coulson and Kutas is also notable because it was present in participants with high joke comprehension scores, and absent in the poor joke comprehenders' ERPs.

\subsection{The present study}

The present study addressed the consequences of bilateral language representation for joke comprehension, a language comprehension task which, in right-handers, is 
hypothesized to recruit right hemisphere participation. ERPs were recorded as left- and right-handed adults read one-line jokes ("A replacement player hit a home run with my girl,") and non-funny control stimuli ("A replacement player hit a home run with my ball,"). If the lateralized ERP effects reported in Coulson and Kutas [16] are related to language lateralization, they might be expected to be attenuated in left-handed subjects. In view of previous work that suggests left-handers' brains are more laterally symmetric than the brains of right-handers, one might expect to see less evidence of lateral asymmetry in left-handers' brainwaves. Alternatively, if previously reported electrophysiological indices of joke comprehension are unrelated to language lateralization, one might expect to see very similar ERP effects in left- and right-handed participants.

\section{Materials and methods}

\subsection{Participants}

Thirty-two UCSD undergraduate volunteers (16 women). Sixteen of these participants were left-handed ( 8 women), and sixteen were right-handed ( 8 women). Handedness was assessed via the Edinburgh inventory [60] to yield each participant's laterality quotient, a number ranging from -100 (completely left-handed) to 100 (completely righthanded). The average LQ for left-handed participants was - 51 (S.E. $=8.67)$, and was 71 for right-handed participants $($ S.E. $=5.31)$. Data was collected from an additional seven participants (four left-handers and three right-handers), but not analyzed due to the presence of artifacts in $40 \%$ or more of the critical trials. All participants were monolingual native English speakers with normal or corrected to normal vision and no history of reading difficulties or neurological/ psychiatric disorders. None of the right-handed participants had a left-handed immediate family member, although six of the left-handed participants (four women) did. All participants received either experimental credit for a course requirement or cash compensation.

Participants' verbal ability was assessed via a short battery of language ability tests including the Peabody Picture Vocabulary Test (PPVT), the Token Test, and a test of Semantic Relations. We also calculated a Sentence Comprehension score for materials presented during the experiment. Sentence Comprehension is thus the percentage of correct answers to the comprehension questions following each sentence (including experimental as well as filler stimuli). From these data, we calculated an overall verbal ability score: $\%$ correct on the PPVT $+\%$ correct on Semantic Relations $+\%$ correct on the Token Test $+\%$ correct Sentence Comprehension (see Table 1). Overall verbal ability scores were used to create groups of high and low verbal ability within each handedness group, as determined by a median split.

Because we observed different ERP effects as a function of handedness and sex, various characteristics of left- and
Table 1

Age, education, and verbal ability scores for participants

\begin{tabular}{|c|c|c|c|}
\hline & Male & Female & Overall \\
\hline \multicolumn{4}{|l|}{ Left-handed } \\
\hline Age & $\begin{array}{l}23 \text { years } \\
(3.25)\end{array}$ & $\begin{array}{l}22.38 \text { years } \\
(4.56)\end{array}$ & $\begin{array}{l}22.69 \text { years } \\
(3.90)\end{array}$ \\
\hline Education & 15 years $(1)$ & $\begin{array}{l}13.88 \text { years } \\
(1.34)\end{array}$ & $\begin{array}{l}14.44 \text { years } \\
(1.2)\end{array}$ \\
\hline PPVT & $94 \%(2 \%)$ & $94 \%(1.2 \%)$ & $94 \%(0.7 \%)$ \\
\hline Semantic Relations & $93 \%(2 \%)$ & $86 \%(5.2 \%)$ & $89 \%(2.78 \%)$ \\
\hline Token Test & $93 \%(1.8 \%)$ & $94 \%(1.8 \%)$ & $93.5 \%(1.28 \%)$ \\
\hline $\begin{array}{l}\text { Sentence } \\
\text { Comprehension }\end{array}$ & $91.6 \%(1.59 \%)$ & $92.6 \%(0.71 \%)$ & $92.1 \%(0.85 \%)$ \\
\hline $\begin{array}{l}\text { Overall Verbal } \\
\text { Ability }\end{array}$ & $92 \%(0.9 \%)$ & $92 \%(1.7 \%)$ & $92 \%(0.98 \%)$ \\
\hline \multicolumn{4}{|l|}{ Right-handed } \\
\hline Age & $\begin{array}{l}23 \text { years } \\
(4.5)\end{array}$ & $\begin{array}{l}20.5 \text { years } \\
(1.88)\end{array}$ & $\begin{array}{l}21.75 \text { years } \\
(1.04)\end{array}$ \\
\hline Education & $\begin{array}{l}14.25 \text { years } \\
(1.5)\end{array}$ & $\begin{array}{l}14.25 \text { years } \\
(1.75)\end{array}$ & $\begin{array}{l}14.25 \text { years } \\
(1.6)\end{array}$ \\
\hline PPVT & $92 \%(1.4 \%)$ & $94 \%(1 \%)$ & $93 \%(0.8 \%)$ \\
\hline Semantic Relations & $89 \%(3.9 \%)$ & $86 \%(3.7 \%)$ & $88 \%(2.6 \%)$ \\
\hline Token Test & $90 \%(2.3 \%)$ & $96 \%(1.2 \%)$ & $93 \%(1.5 \%)$ \\
\hline $\begin{array}{l}\text { Sentence } \\
\quad \text { Comprehension }\end{array}$ & $89.9 \%(1.29 \%)$ & $93.1 \%(0.97 \%)$ & $91.5 \%(0.89 \%)$ \\
\hline $\begin{array}{l}\text { Overall Verbal } \\
\text { Ability }\end{array}$ & $90 \%(1.2 \%)$ & $92 \%(1.3 \%)$ & $91 \%(0.9 \%)$ \\
\hline
\end{tabular}

right-handed males and females have been listed in Table 1 . The four participant groups were matched for age, years of education, and performance on tests of verbal ability.

\subsection{Materials}

Each participant silently read 240 sentences including 80 Jokes, one-line jokes (e.g., "A replacement player hit a homerun with my girl"), 80 Straights, one-line jokes that ended with a cloze-matched non-joke ending rather than the joke ending (e.g., "A replacement player hit a homerun with my ball"), and 80 Expecteds, filler sentences with predictable endings (e.g., "My green car blocked the narrow driveway"). Sample experimental stimuli can be found in Table 2. The 80 filler sentences were the same in both lists, while the 160 pairs of experimental sentences were presented in two different lists. Joke endings in one list were replaced by straight endings in the other, and vice versa so that no participant saw both versions of the experimental stimuli. Each participant viewed one list. Following each sentence, a statement designed to test comprehension of the sentence was presented and the participant's response was indicated by a button-press.

Inspection of published word association norms [13] suggested that straight endings were no more likely than joke endings to be preceded by associates-presumably because both sorts of endings are unexpected in the context. Approximately $12 \%$ of the joke endings were preceded by a semantic associate, as were $10 \%$ of the straight endings, though the mean association level was slightly higher for the 
Table 2

Sample experimental stimuli

\begin{tabular}{lll}
\hline Sentence & Joke ending & $\begin{array}{l}\text { Straight } \\
\text { ending }\end{array}$ \\
\hline $\begin{array}{l}\text { By the time Mary had her fourteenth child, } \\
\text { she'd run out of names to call her }\end{array}$ & husband. & offspring. \\
$\begin{array}{l}\text { A device for finding furniture in the dark } \\
\text { is a }\end{array}$ & shin. & candle. \\
$\begin{array}{l}\text { My doctor has never violated his oath: the } \\
\text { oath he took years ago to become a }\end{array}$ & millionaire. & practitioner. \\
$\begin{array}{l}\text { The only place where you can find people } \\
\text { who spend all their time minding their }\end{array}$ & cemetery. & bank. \\
$\begin{array}{l}\text { own business is the } \\
\text { It is hard to raise a family nowadays, } \\
\text { especially in the }\end{array}$ & morning. & country. \\
\hline
\end{tabular}

joke (1.3\%) than straight (1.6\%) endings. Although not all of the words in our stimuli were contained in the Edinburgh Associative Thesaurus, the generally low level of association found is unlikely to result in lexical priming effects.

Sentence-final words in the joke and straight conditions were also matched for cloze probability (all jokes $=0.9 \%$ $($ S.E. $=1.3 \%)$, all straights $=2.2 \%($ S.E. $=1.5 \%))$, as assessed via a separate off-line sentence completion task in which 80 people from the same subject pool as the main experiment participated. Cloze probability of the "expected" completions in the filler stimuli was $80.8 \%$ $($ S.E. $=11.3 \%)$. All sentence-final words were matched for word length $($ List 1: jokes $=6.8($ S.E. $=1.6)$, straights $=6.8$ $($ S.E. $=1.6) ;$ List 2: jokes $=6.8($ S.E. $=1.6)$, straights $=6.8$ $($ S.E. $=1.6)$; all fillers $=6.8($ S.E. $=1.0))$ and frequency per million as assessed by the Kucera and Francis database (List 1 : jokes $=47.2($ S.E. $=53.2)$, straights $=46.8($ S.E. $=52)$; List $2:$ jokes $=47.0($ S.E. $=53.3)$, straights $=47.4($ S.E. $=51.8)$; all fillers $=47.1($ S.E. $=53.2)$ ).

\subsection{Procedure}

Participants sat in an electrically shielded, sound-attenuated chamber and read sentences presented one word at a time in rapid serial succession (RSVP) on a computer monitor. Participants were seated approximately $40 \mathrm{in}$. from the screen and instructed to read each sentence for comprehension. After each sentence, a comprehension sentence was presented (in its entirety) and participants were instructed to judge whether or not it was consistent with the first sentence, and to respond by making a yes or no button press (e.g., sentence: "Every time I wear my spring coat in the rain, it damages the springs." comprehension sentence: "Water isn't good for my coat." correct response: YES) Response hands were counterbalanced across participants.

The first sentence of each pair was preceded by a fixation cross to orient the participant to the center of the screen. Each word of the first sentence was then presented in the center of the screen for a fixed duration of $200 \mathrm{~ms}$ with an inter-stimulus interval (ISI) that varied as a function of word-length (i.e., $200 \mathrm{~ms}+32 \mathrm{~ms} /$ character). The final, target word of each sentence was followed by a blank screen for $2500 \mathrm{~ms}$ before the presentation of the comprehension sentence. The comprehension sentence was then presented for $4 \mathrm{~s}$, and followed by a blank screen for $2 \mathrm{~s}$ until the next trial began.

\subsection{Electroencephalogram (EEG) recording}

Participants' EEG was recorded from 29 tin electrodes mounted in an Electro-Cap, referenced to the left mastoid. Electrode sites included the following 10-20 sites: FP1, FPZ, FP2, F7, F3, FZ, F4, F8, FT7, FC3, FCZ, FC4, FT8, C3, CZ, C4, TP7, CP3, CPZ, CP4, TP8, T5, P3, PZ, P4, T6, $\mathrm{O} 1, \mathrm{OZ}$, and $\mathrm{O} 2$ [39,59]. Horizontal eye movements were monitored via a bipolar montage of electrodes placed at the outer canthi. Blinks were monitored via an electrode placed on the infraorbital ridge of the right eye and referenced to the left mastoid. The EEG was also recorded at the right mastoid, and all data were re-referenced off-line to the average of the right and left mastoids. Electrode impedances were kept below $5 \mathrm{k} \Omega$. EEG was processed through SA Instrumentation amplifiers set at a band pass of 0.01-40 Hz. EEG was continuously digitized at $250 \mathrm{~Hz}$ and stored on a hard disk.

\subsection{Data analysis}

The EEG data recorded from each participant was visually inspected, and trials were rejected when contaminated by artifacts such as excessive vertical or horizontal electrooculographic potentials, excessive muscle activity, amplifier blocking or drift. Artifact contamination in the digitized data was determined off-line by using computer algorithms that calculated peak-to-peak voltage amplitudes, voltage deviations from baselines and polarity inversions between the lower eye and prefrontal recordings. In the joke condition, the mean rejection rate was $18.0 \%$, S.D. $=12.3$, S.E. $=2.2$ (Left-handers' mean $=14.4 \%$, S.D. $=10.0$, S.E. $=2.5$; Righthanders' mean $=21.6 \%$, S.D. $=13.6$, S.E. $=3.4$ ). In the straight condition, the mean rejection rate was $19.2 \%$, S.D. $=12.1$, S.E. $=2.1$ (Left-handers' mean $=16.3 \%$, S.D. $=10.5$, S.E. $=2.6$; Right-handers' mean $=22.2 \%$, S.D. $=13.1$, S.E. $=3.3$ ). In the filler condition, the mean rejection rate was $20.4 \%$, S.D. $=10.8$, S.E. $=1.9$ (Left-handers' mean $=18.2 \%$, S.D. $=8.8$, S.E. $=2.2$; Right-handers' mean $=22.7 \%$, S.D. $=12.4$, S.E. $=3.1$ ). Participants with artifact rejection rates of more than $40 \%$ were excluded from the study (four left-handers and three right-handers).

ERPs were computed for recording epochs extending from a $100-\mathrm{ms}$ pre-stimulus onset baseline to $920 \mathrm{~ms}$ poststimulus onset. Averages of artifact-free ERP trials were calculated for each type of target word (jokes, straights, expecteds). ERPs were quantified by measuring the mean amplitude of the waveforms $300-500,500-700$, and $700-$ $900 \mathrm{~ms}$ post-word onset relative to a $100-\mathrm{ms}$ pre-stimulus baseline. Measurements were subjected to repeated measures ANOVA with three between-subjects group variables: hand- 
Table 3

Percent correct on comprehension questions (standard error)

\begin{tabular}{lrr}
\hline & Left-handers & \multicolumn{1}{l}{ Right-handers } \\
\hline Males & $91.63 \%(1.59 \%)$ & $89.88 \%(1.29 \%)$ \\
Females & $92.63 \%(0.71 \%)$ & $93.3 \%(0.97 \%)$ \\
Overall & $92.1 \%(0.85 \%)$ & $91.5 \%(0.89 \%)$ \\
\hline
\end{tabular}

edness (right/left), verbal ability (high/low), and sex (male/ female), and three within-subjects variables: ending (joke/ straight), hemisphere (left/right), and anterior/posterior scalp site (seven levels at central and medial sites and four levels at lateral sites). All $p$ values were corrected using the HuhynFeldt correction. However, for clarity, we report original degrees of freedom. Central sites refer to: FPZ, FZ, FCZ, CZ, CPZ, PZ, and OZ. Medial sites refer to: FP1, FP2, F3, F4, $\mathrm{FC} 3, \mathrm{FC} 4, \mathrm{C} 3, \mathrm{C} 4, \mathrm{CP} 3, \mathrm{CP} 4, \mathrm{P} 3, \mathrm{P} 4, \mathrm{O} 1$, and $\mathrm{O} 2$. Lateral sites refer to: F7, F8, FT7, FT8, TP7, TP8, T5, and T6.

\section{Results}

\subsection{Sentence comprehension}

Overall, performance on comprehension questions was excellent in all groups, as can be seen from Table 3. To facilitate more accurate experimental comparisons, trials in which the comprehension judgment task was answered
Table 4

Omnibus analysis of ERP amplitude in the N400 time window

\begin{tabular}{llll}
\hline $\begin{array}{l}\text { Mean amplitude 300-500 ms } \\
\text { post-stimulus onset }\end{array}$ & $F$ value & $p$ value & Epsilon \\
\hline $\begin{array}{l}\text { Midline electrodes } \\
\text { Ending } \times \text { Ant/Post }\end{array}$ & $F(6,144)=5.75$ & $p<0.01$ & 0.4746 \\
$\begin{array}{l}\text { Handedness } \times \text { Verbal Ability } \times \\
\quad \text { Ending } \times \text { Ant/Post }\end{array}$ & $F(6,144)=2.39$ & $p=0.07$ & 0.4746 \\
& & & \\
Medial electrodes & & & \\
$\begin{array}{l}\text { Ending } \times \text { Hemisphere } \\
\text { Ending } \times \text { Hemisphere } \times \\
\quad \text { Ant/Post }\end{array}$ & $F(1,24)=5.31$ & $p<0.05$ & \\
Handedness $\times$ Sex $\times$ Ending $\times$ & $F(6,144)=2.75$ & $p=0.07$ & 0.4087 \\
$\quad$ Ant/Post & & & \\
& & & \\
$\begin{array}{l}\text { Lateral electrodes } \\
\text { Handedness } \times \text { Ending } \times\end{array} \quad$ Hemisphere $\times$ Ant/Post & $F(3,72)=4.04$ & $p<0.05$ & 0.7678 \\
Handedness $\times$ Verbal Ability $\times$ & $F(3,72)=4.74$ & $p<0.05$ & 0.5528 \\
$\quad$ Ending $\times$ Ant/Post & & & \\
\hline
\end{tabular}

incorrectly were not included in the analyses of the ERP data.

\subsection{Event-related brain potentials}

ERPs elicited by joke and straight endings in left- and right-handers can be seen in Fig. 1. Typical of ERPs to visually presented words, all stimuli elicited N1, P2, and

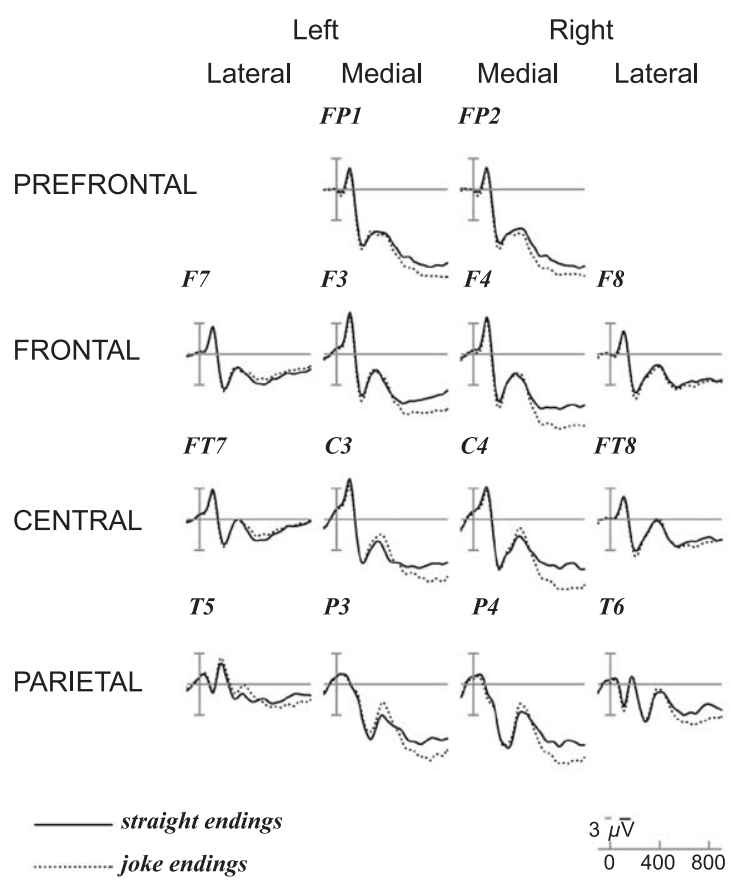

Left Handers

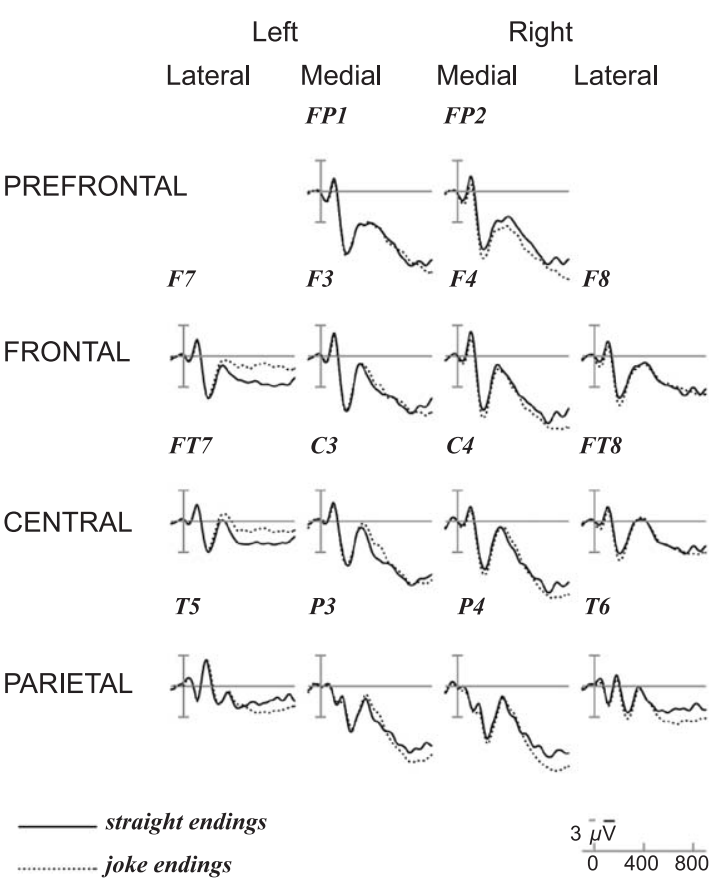

Right Handers

Fig. 1. Joke effects in left- and right-handers. ERPs elicited by the last word of one-line jokes (dotted) and straight endings (solid) to the same sentences. Negative voltage is plotted up in this and all subsequent figures. Compare the sustained negativity elicited by jokes $500-900$ ms post-onset in the right-handers with left-handers' ERPs at F7. 
Left Handers

FP1 FP2

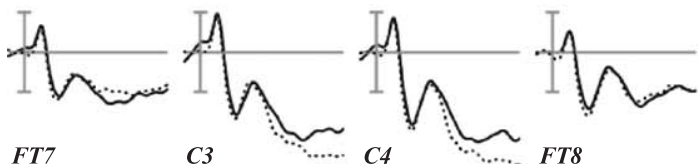

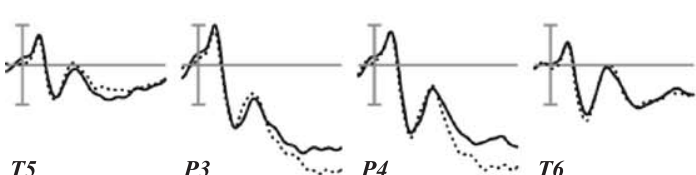

T5 $P 3 \quad \overbrace{P 4}$

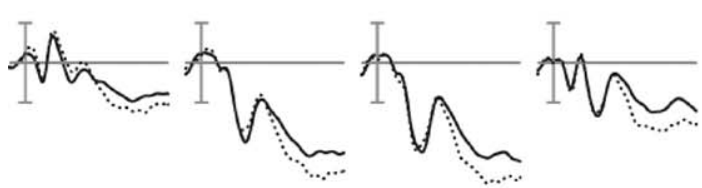

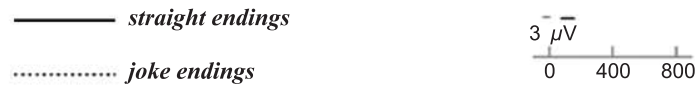

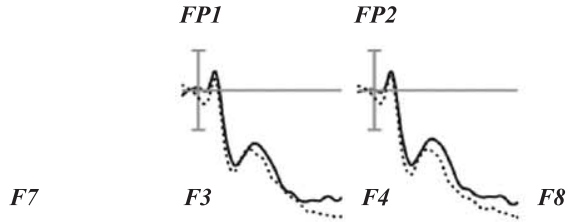

Right Handers

FP1 FP2

High Verbal Ability
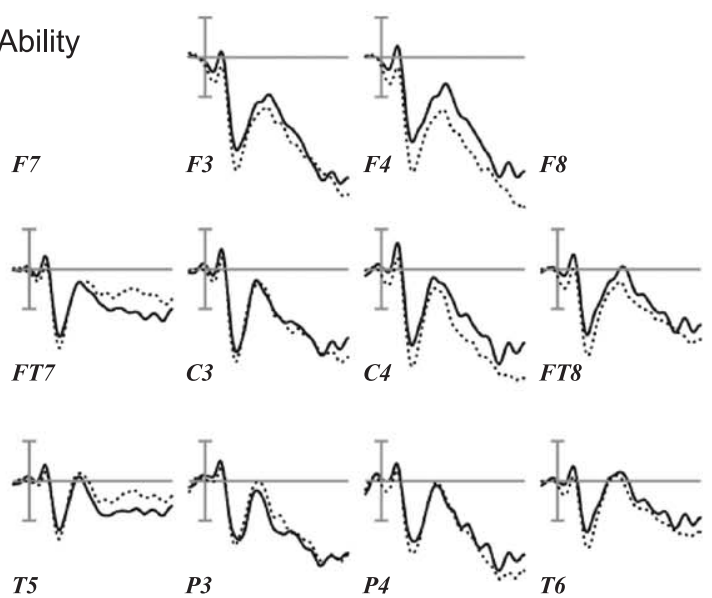

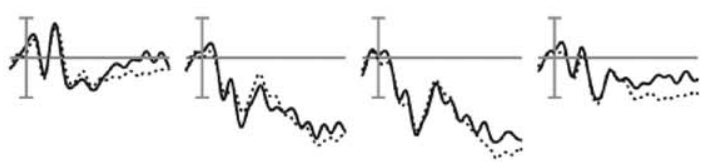
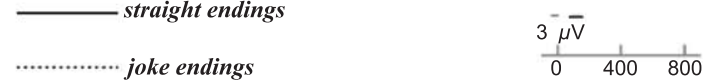

FP1

FP2

Low Verbal Ability

F7
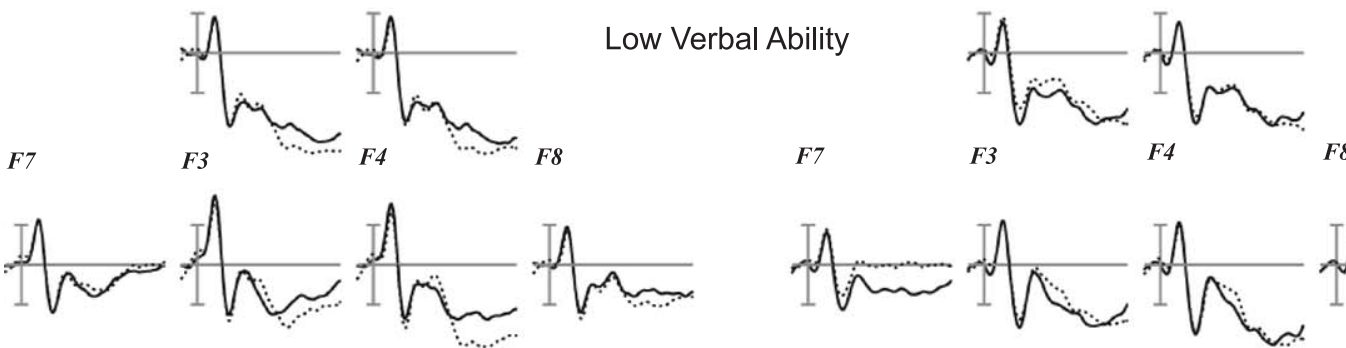

FT7

C4

FT8

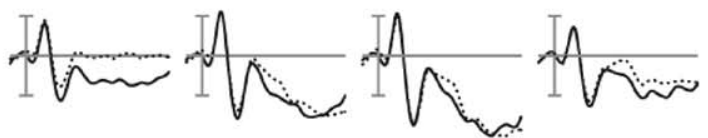

FT7

C3

C4 FT8<smiles>C=CCCCCCCCCCCCC(C)(C)C</smiles>

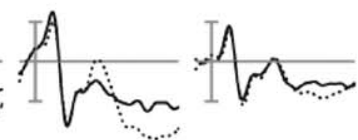

T5

P3

P4

T6

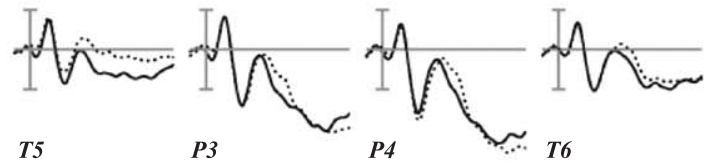

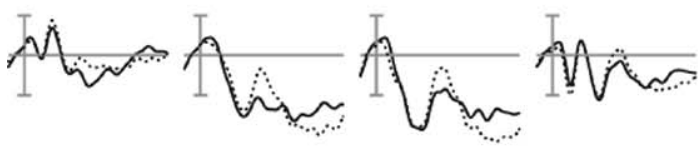
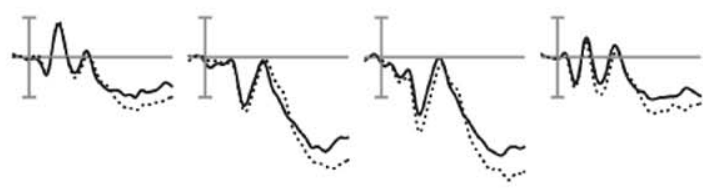

straight endings

joke endings

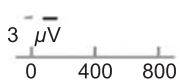

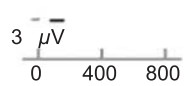

Fig. 2. N400 joke effect. ERPs elicited by the last word of one-line jokes (dotted) and straight endings (solid) to the same sentences in high (top) and low (bottom) verbal left- and right-handers. N400, typically prominent at P3 and P4, is evident only in low verbal left-handers. 
N400 components. In the latter part of the epoch (500-900 ms post-stimulus), ERPs were characterized by a positivegoing wave. No effects were apparent on the N1 and P2 components. Below, we report analysis of ERPs measured in the interval of the N400 component (300-500 ms postonset), and the interval of the late positivity (500-900 ms post-onset).

\section{3. $300-500 \mathrm{~ms}$}

Analysis in this time window was intended to capture the N400 component, a broadly distributed negativity whose amplitude is sensitive to the difficulty of lexical integration. Although joke endings did elicit slightly more negative ERPs than the straight endings over central and parietal sites among left-handers (see C3, C4, P3, and P4 in Left Handers' data in Fig. 1), the overall effect of ending on ERP amplitude was spatially restricted and varied as a function of participant groups. Results of the omnibus analysis can be seen in Table 1. Interactions between ending and the anterior posterior factor result because ERPs to jokes were slightly more positive than straights of prefrontal sites (FP1 and FP2), and more negative than straights over central and parietal sites. The posterior negativity is presumed to reflect the $\mathrm{N} 400$, although the effect was slightly larger over LH electrode sites (cf. P3 to P4). While the N400 is typically larger over RH electrode sites, the observed scalp distribution may be due to the beginning of the overlapping late positivity at pre-frontal sites, which was larger in the joke condition.

There were no effects of handedness or sex, individually or in a two-way interaction with sentence type, in any of the electrode-site regions (all $F$ 's $\leq 1.46$ ). Analysis of data recorded at lateral electrodes revealed a reliable interaction between handedness, ending and electrode site factors (see Table 4). Moreover, analysis of ERPs recorded at midline and medial electrode sites revealed a trend for four-way interactions between handedness, verbal ability, ending, and electrode site, which was significant in the lateral analysis (see Table 4). These interactions motivated further statistical analyses of each handedness group individually, as well as analyses of high and low verbal ability groups within each handedness group.

These post hoc analyses indicated that the reliable interaction in the omnibus analysis between handedness and ending at lateral sites results because there was a spatially restricted joke effect at left anterior sites (F7 and FT7) in right- but not left-handed participants (see Fig. 1). Analysis of data recorded from right-handers revealed an interaction between sentence-type and electrode site (lateral: Ending $\times$ Hemisphere $\times$ Ant/Post, $F(3,36)=3.40, p=0.050$, $e=0.6571$ ), reflecting the enhanced negativity to jokes at left anterior recording sites F7 and FT7. However, analysis of data recorded from left-handers revealed no significant effects of sentence-type in this time window ( $F$ 's $\leq 1.88$ ).

The trend towards an interaction in the omnibus analysis of handedness, sex, ending type, and the anterior/posterior factor is probably due to the fact that a positive-going response to jokes over pre-frontal electrode sites Fp1, Fpz, and Fp2 is evident only in the right-handed females' ERPs (see Fig. 3), while the parietal negativity was most evident among the left-handed males. Post hoc analysis of data collected from medial scalp sites in the 16 righthanded participants revealed a marginal interaction between sex, ending, and scalp site (Sex $\times$ Ending $\times$ Ant $/$ Post, $F(6,72)=2.28, p=0.099, e=0.4307)$ that results because of a (non-significant) positive-going response to jokes over the pre-frontal electrode $(\mathrm{FPz})$ among the females, and a (non-significant) pre-frontal negativity among the males. In contrast, a similar analysis of the 16 left-handers' ERPs revealed no interactions between sex, sentence type, and any of the electrode site factors (all $F$ 's $<1$ ). Given the small number of participants (8) in each sub-group, these apparent sex differences may simply reflect individual variability.

In contrast to the non-significant sex differences in this latency window, differences reflecting verbal ability groups were more robust, and are more likely to reflect physiological differences related to the verbal ability factor. The interaction in the overall analysis between handedness, verbal ability, and ending type results because the centroparietal negativity elicited $300-500 \mathrm{~ms}$ post-onset is evident only in the low verbal left-handers (see C3, C4, P3, and P4 in Fig. 2) (low VA left-handers, lateral: Ending $\times$ Ant/Post, $F(3,21)=3.75, p<0.05, e=0.7265)$, while the enhanced anterior negativity is evident only among the low verbal right-handers (see F7, F8, FT7, and FT8 in Fig. 2) (low-

Table 5

Omnibus analysis in latency range of the late positivity and sustained anterior negativity

\begin{tabular}{|c|c|c|c|}
\hline $\begin{array}{l}\text { Mean amplitude } 500-900 \mathrm{~ms} \\
\text { post-stimulus onset }\end{array}$ & $F$ value & $p$ value & Epsilon \\
\hline \multicolumn{4}{|l|}{ Midline analyses } \\
\hline Ending & $F(1,24)=9.92$ & $p<0.01$ & \\
\hline Ending $\times$ Ant $/$ Post & $F(6,144)=2.42$ & $p=0.07$ & 0.508 \\
\hline $\begin{array}{l}\text { Handedness } \times \text { Sex } \times \text { Ending } \times \\
\text { Ant } / \text { Post }\end{array}$ & $F(6,144)=4.48$ & $p=0.07$ & 0.508 \\
\hline \multicolumn{4}{|l|}{ Medial analyses } \\
\hline Ending & $F(1,24)=8.36$ & $p<0.01$ & \\
\hline Ending $\times$ Hemisphere & $F(1,24)=8.13$ & $p<0.01$ & \\
\hline $\begin{array}{l}\text { Ending } \times \text { Hemisphere } \times \\
\text { Anterior/Posterior }\end{array}$ & $F(6,144)=3.62$ & $p<0.01$ & 0.927 \\
\hline $\begin{array}{l}\text { Handedness } \times \text { Sex } \times \text { Ending } \times \\
\text { Hemisphere }\end{array}$ & $F(1,24)=7.92$ & $p<0.05$ & \\
\hline \multicolumn{4}{|l|}{ Lateral analyses } \\
\hline Ending $\times$ Hemisphere & $F(1,24)=11.71$ & $p<0.01$ & \\
\hline Ending $\times$ Ant $/$ Post & $F(3,72)=13.08$ & $p<0.0001$ & 0.806 \\
\hline $\begin{array}{l}\text { Ending } \times \text { Hemisphere } \times \\
\text { Ant } / \text { Post }\end{array}$ & $F(3,72)=5.33$ & $p<0.01$ & 0.806 \\
\hline $\begin{array}{l}\text { Handedness } \times \text { Ending } \times \\
\text { Hemisphere } \times \text { Ant } / \text { Post }\end{array}$ & $F(3,72)=4.07$ & $p<0.05$ & 0.806 \\
\hline $\begin{array}{l}\text { Handedness } \times \text { Sex } \times \text { Ending } \times \\
\text { Hemisphere }\end{array}$ & $F(1,24)=5.52$ & $p<0.05$ & \\
\hline
\end{tabular}


verbal right-handers, lateral: Ending $\times$ Ant/Post, $F(3,21)=$ 8.84, $p<0.01, e=0.7829$ ). In Fig. 2, the posterior N400-like potential is evident in the low VA left-handers' ERPs, but not in the other groups.

\section{4. $500-900 \mathrm{~ms}$}

In the time window 500-900 ms post-onset, ERPs to joke endings were generally more positive than to straight
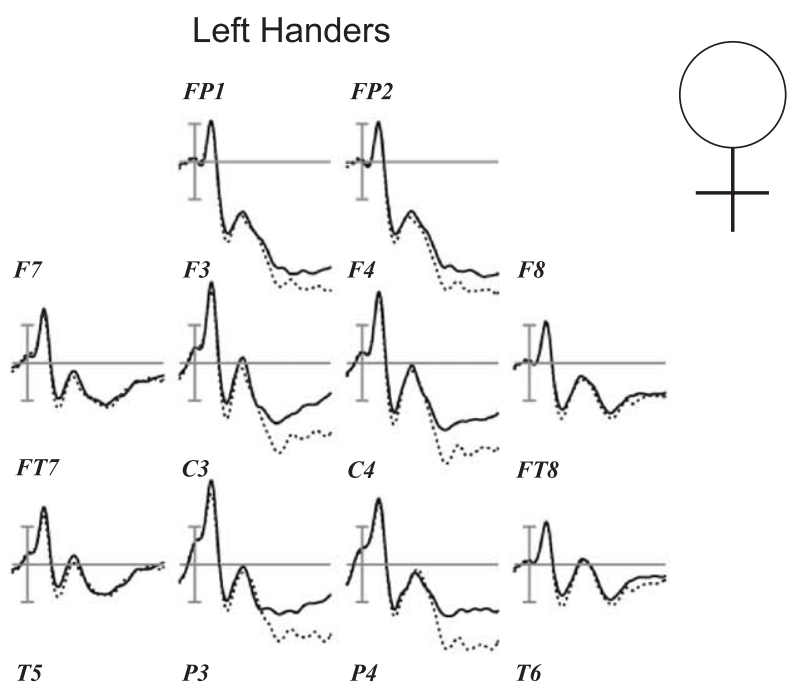

Right Handers
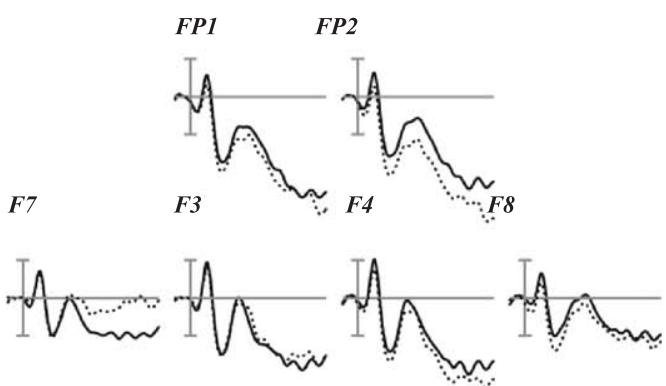

$\begin{array}{llll}\text { FT7 } & \text { C3 } & \text { C4 } & \text { FT8 }\end{array}$

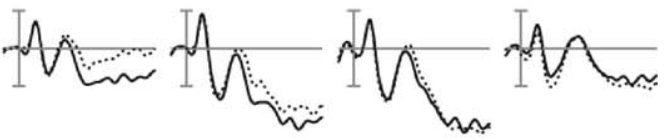

$\begin{array}{llll}T 5 & P 3 & P 4 & T 6\end{array}$
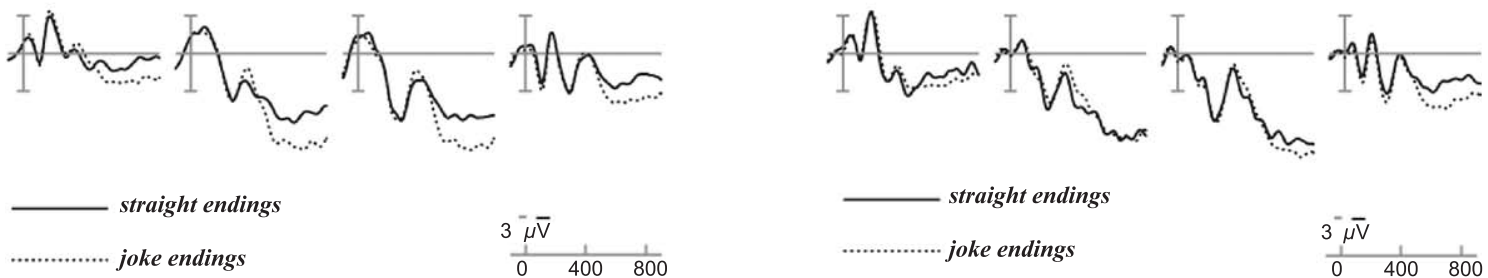

FP1

FP2

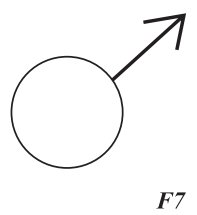

FP1 FP2
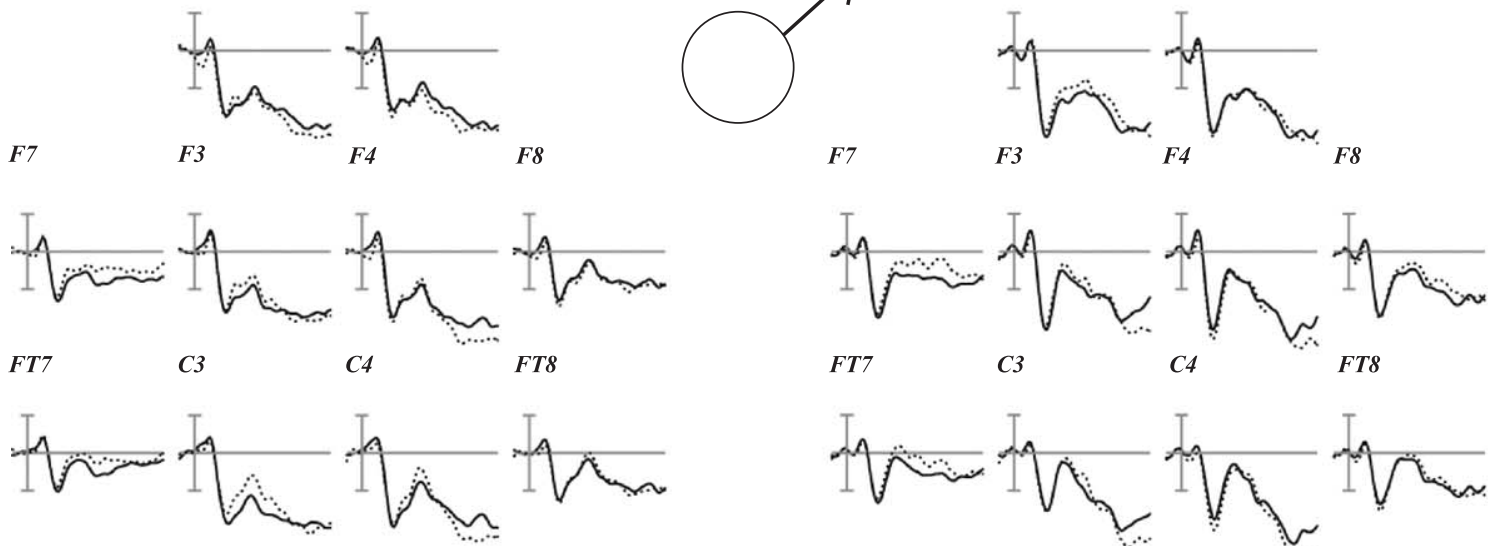

C4 FT8

FT7

C3

C4

FT8

T5

P3

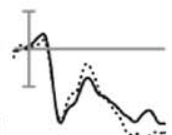<smiles>CCCCC(C)C</smiles>

I

T5

P3<smiles>[Te]</smiles>

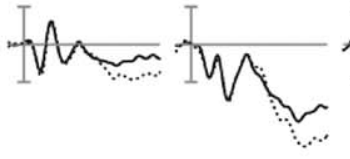

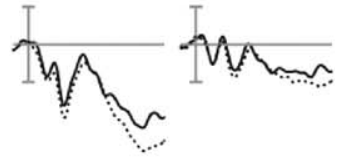

straight endings

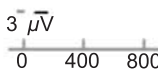

Fig. 3. Sex and handedness. ERPs elicited by the last word of one-line jokes (dotted) and straight endings (solid) to the same sentences in female (top) left- and right-handers, and male (bottom) left- and right-handers. In both left- and right-handed males, the late positivity 500-900 ms appears larger over right hemisphere recording sites (cf. P3 and P4). In female right-handers, the late positivity was evident only over pre-frontal electrode sites (FP1 and FP2). In female left-handers, the late positivity was larger and more broadly distributed than in other groups, and was bilaterally symmetric. 
endings, especially at centro-parietal electrode sites over the right hemisphere (C4 and P4). ERPs at left anterior electrode sites (F7 and FT7), however, were marked by a sustained negativity to the jokes relative to the straight endings. Joke effects on the late positivity and the anterior negativity were suggested in the analyses by main effects of ending and interactions between ending, hemisphere, and the anterior-posterior factor (see Table 5). Moreover, the ending effect was further qualified by interactions with the handedness and sex of participants (see Table 5). These interactions were followed up by post hoc analyses of each of the individual subgroups (left-handed males, left-handed females, right-handed males, right-handed females).

Among the right-handed females, there was a trend for more positive ERPs to jokes than to straights at medial sites (Medial: Ending, $F(1,7)=5.08, p=0.06$ ). At lateral sites, the most obvious effect was the sustained negativity to joke as compared to straight endings at left anterior sites F7 and FT7 (see Fig. 3) (Lateral: Ending $\times$ Hemisphere, $F(1,7)=12.62$, $p<0.01$; Ending $\times$ Ant/Post, $F(3,21)=5.45, p<0.05$, $e=0.382$; Ending $\times$ Hemisphere $\times$ Ant $/$ Post, $F(1,7)=3.21$, $p<0.05, e=0.599)$. In the group of right-handed males, ERPs to jokes were slightly more positive than to straights (see Fig. 3), an effect which though not reliable at medial sites (Right-handed males, Medial: Ending, $F(1,7)=2.83$, $p=0.14$ ), was significant at lateral sites (for instance, T5) (Ending $\times$ Ant/Post, $F(3,21)=4.97, p<0.05, e=0.514$ ). A small joke effect can be seen on the sustained anterior negativity (see ERPs recorded from F7 in Fig. 3), however, this difference was not reliable (Lateral: Ending $\times$ Hemisphere $\times$ Ant $/$ Post, $F(3,21)=2.01, p=0.17, e=0.66)$. The sustained anterior negativity was larger and more robust among right-handed women than men.

Analysis of data recorded from left-handed males indicated that ERPs to jokes were more positive than to straights at medial sites, and this effect was larger toward the back of the head over the right hemisphere (see, e.g., P4 in Fig. 3) (Ending $\times$ Hemisphere, $F(1,7)=8.78, p<0.05$; Ending $\times$ Hemisphere $\times$ Ant/Post $, F(6,42)=6.82, p<0.01$, $e=0.412$ ). At lateral sites there were no effects in the males, notably no joke effect at left anterior sites. Among the lefthanded females, ERPs to jokes were more positive than to straight endings (Medial: Ending, $F(1,7)=18.54, p<0.01$; Lateral: Ending, $F(1,7)=10.42, p<0.05)$. In contrast to the right-lateralized positivity in the left-handed males, among the females the positivity was bilaterally symmetric (see Fig. 3) (Lateral, Medial: Ending $\times$ Hemisphere, $F$ 's $<1$ ). Further, no joke effect was evident over left anterior sites (Lateral: Ending $\times$ Hemisphere $\times$ Ant/Post, $F(3,21)<1)$.

\subsection{Summary}

We compared ERPs elicited by the last word of sentences that ended as jokes with equally unexpected "straight" endings to the same sentences. In right-handers' ERPs, jokes elicited an enhanced negativity at left anterior (F7 and FT7) electrode sites $300-500 \mathrm{~ms}$ after stimulus onset. This effect was absent from left-handers' ERPs. In contrast, a parietal N400-like negativity was observed in low (but not high) verbal left-handers' ERPs (see Fig. 2). Between 500 and $900 \mathrm{~ms}$ post-stimulus onset, ERPs to jokes were more negative over left anterior sites (slow sustained anterior negativity) and more positive over posterior sites (LPC). However, effects in this latter latency range differed as a function of the handedness and sex of the participant.

Among right-handed men, the LPC was largest over centro-parietal electrode sites; among the women, it was evident only over anterior electrode sites FP1, FP2, and F4 (see Fig. 3). The LPC joke effect in left-handers' ERPs was larger than in right-handers' (see Fig. 1), and it too differed as a function of sex (see Fig. 3). Among left-handed men, the LPC was largest over centro-parietal electrode sites, especially over the RH. This LPC joke effect was larger and more bilaterally distributed in ERPs collected from lefthanded women (Fig. 3). The slow sustained anterior negativity was observed in ERPs collected from both righthanded men and women, but not in ERPs collected from either left-handed men or left-handed women (see Fig. 3).

\section{Discussion}

To address the impact of differences in language lateralization on joke comprehension, ERPs were recorded as leftand right-handed adults read one-line jokes ("A replacement player hit a home run with my GIRL," and non-funny control stimuli ("A replacement player hit a home run with my BALL,"). As in our previous study of joke comprehension, the joke endings elicited three ERP effects. First, jokes elicited more negative ERPs than straight endings 300-500 ms post-onset. Between 500 and $900 \mathrm{~ms}$, jokes elicited a late positivity over most sites, and a slow sustained anterior negativity over left anterior sites F7 and FT7. These effects differed as a function of various group variables, including participants' handedness, verbal ability, and sex as discussed below. However, joke comprehension as indexed by performance on comprehension questions was excellent in all of the participant groups tested. Thus, group differences in ERP effects are presumed to reflect differences in cerebral organization.

\subsection{Negativity $300-500 \mathrm{~ms}$}

As noted above, in a previous study of joke comprehension, Coulson and Kutas [16] report that a subset of their jokes elicited a larger amplitude N400 component than nonfunny control stimuli. In the present study, however, an N400-like response was observed only in ERPs collected from low verbal left-handers. Among right-handers, the negative-going ERP effect in this latency range was evident only over anterior left lateral electrode sites. The restricted scalp distribution of the right-handers' negative-going ERP 
effect clearly differs from that of the N400, a broadly distributed negativity largest at centro-parietal electrode sites, and typically larger over the RH.

However, in Coulson and Kutas' [16] study, only high constraint jokes elicited larger amplitude N400 than their straight endings. That is, in cases such as "I asked the hostess if she remembered me from the party last year, and she said that she never forgets a," where the sentence context leads participants to expect a particular word (e.g., "face"), joke endings ("dress") elicited larger N400 than unexpected straight endings ("name"). However, in low constraint sentences such as "My husband took all the money we had been saving to buy a new car and blew it all at the," joke ("movies") and straight ("tables") endings elicited equal amplitude N400.

The absence of an N400 joke effect in the present study may be due to the fact that a large percentage of the jokes used here were low constraint jokes. ${ }^{1}$ Further, in the present study, one third of the sentences (approximately 33\%) ended as jokes, in contrast to the earlier study in which only $19 \%$ of the sentences ended as jokes. The relatively high percentage of jokes in the present study may have promoted a joke "set" among participants that facilitated joke processing, thus eliminating the processing difficulty signaled by the N400 joke effect. Our observation of a small N400 joke effect among the low verbal left-handers may indicate that - for this sub-group - relatively more bilateral language representation has a detrimental effect on the lexical integration of joke endings.

In ERP language studies, several investigators have varied the proportion of syntactic anomalies in experimental materials, and observed a decrease in the amplitude of the P600 component typically elicited by such stimuli as the number of anomalies increases $[17,18,27]$. Further, while no published studies describe the effect of increasing the proportion of sentences with identifiable semantic characteristics (such as the proportion of jokes), a number of investigators have varied the proportion of related word pairs in priming studies. N400 priming effects have been observed to be larger in stimulus sets that contain a high than a low proportion of related word pairs, as if the engagement of controlled processes enhances the facilitatory effect of context $[12,38]$. It is then, at least, plausible that the ability to anticipate jokes in our stimulus set aided the lexical integration of joke endings and led to reduced N400 effects.

\subsection{Late positivities}

In the later time windows examined, jokes elicited more positive ERPs than straights, although the scalp distribution

\footnotetext{
1 We found it difficult to assemble a large number of high constraint jokes that conformed to the requirements of our design. It turns out that most one-line jokes are "low cloze," i.e., they elicit a wide variety of responses on a sentence completion task.
}

of these positivities differed as a function of handedness and sex (see Fig. 3). Among right-handed women, the late positivity was only evident over pre-frontal electrode sites and was larger over the RH. Among both left- and righthanded men, the topography of the positive-going joke effect matched that of the LPC: It was centro-parietal and larger over RH scalp sites. Among left-handed women, the positivity was largest over centro-parietal sites, but was also evident over pre-frontal electrodes. Moreover, the late positivity was both larger and more bilateral in left-handed women than in left-handed men.

The late positivity thus differs both as a function of participants' sex and their handedness. This finding is consistent with the suggestion that language is less lateralized in women than men [42]. Further, meta-analysis of studies utilizing post-mortem measures, as well as computerized axial tomography (CAT) and magnetic resonance imaging (MRI) of living people indicates that left-handers have larger corpus callosal areas than right-handers, and that, relative to their overall brain size, women have larger corpus callosal areas than do men $[23,75]$. Such anatomical differences have been argued to lead to more efficient interhemispheric communication in left-handers and women, with potential consequences for information processing $[1,37]$. Of course, effects of sex and handedness on the size of the corpus callosum need not be additive.

Handedness has previously been found to affect the amplitude and latency of the P3 component in an auditory stimulus discrimination task, as the $\mathrm{P} 3$ amplitude was larger over anterior electrode sites and its latency was shorter in left-handers than in right-handers [1]. In both auditory and visual oddball paradigms, P3 amplitude is larger in lefthanders than right-handers and larger in women than men [37]. Group differences in P3 amplitude and latency have been argued to result from more efficient interhemispheric communication in subject populations with greater corpus callosal areas [1,37]. This interpretation is supported by findings that argue for the importance of interhemispheric communication in the generation of the P3 component $[45,76,77]$.

In the present study, the amplitude of the late positivity elicited by jokes was greater in left than right-handers, an effect driven mainly by the amplitude of ERPs collected from left-handed women. The relationship between late positivities in the present study and the $\mathrm{P} 3$ component is unknown. However, late positivities in ERPs elicited by language stimuli have previously been shown to be sensitive to some of the same experimental manipulations as the P3b component [17,18]. Moreover, previous investigators have suggested a relationship between late positivities elicited by jokes and the P3 component [16,21].

The functional significance of the late positivities elicited by jokes in comparison to straight controls is currently unclear. However, in our previous ERP study of joke comprehension, late positivities were observed in participants deemed to be good joke comprehenders, but not in 
poor joke comprehenders [16], suggesting its elicitation is contingent on actually getting the joke. A posterior positivity similar to that in the left- and right-handed men as well as the left-handed women in the current study has also been observed in a study that compared words used in literal as opposed to metaphorical senses ("Before dinner there was almost always a prayer," "Their last shot in that game was only a prayer,") [15]. Coulson and Van Petten suggested the late positivity in the latter paradigm might reflect the recovery of additional information from semantic memory needed to understand the metaphor. This interpretation fits well with the present study where the joke endings surely would have required the recovery of more information from memory than the straight endings, which were explicitly designed to be consistent with the context evoked by the sentence. Testing this hypothesis, however, would require varying the information demands more systematically and observing its effect on the amplitude of the late posterior positivity.

In any case, the most laterally symmetric ERPs were recorded from left-handed women - the participant group that might be expected to have the greatest corpus callosal areas. In the other three groups, the late positivity to jokes was larger over the RH. Only in the left-handed females was the late positivity bilaterally symmetric. However, in our sample the sex of the left-handed participants was partially confounded by familial sinistrality as four out of the eight females reported having left-handers in their immediate family, while only two out of the eight males did (none of the right-handers had left-handers in their immediate family). It is even possible (albeit a remote possibility) that group differences in ERP effects result from differences in brain morphology skull thickness, or cranial differences rather than functionally significant physiological differences [19]. The relationship between group differences in brain anatomy and observed ERP effects requires further examination using both electrophysiological and radiological techniques.

\subsection{Sustained anterior negativity 500-900 ms}

In a previous study [16], compared to non-joke control stimuli, jokes elicited a sustained anterior negativity 500 $900 \mathrm{~ms}$ post-onset over a few anterior left lateral electrode sites. This effect was argued to index frame-shifting necessary to get a joke because it was evident in ERPs to both high and low constraint stimuli, and was absent from ERPs recorded from poor joke comprehenders, i.e., people who had difficulty getting the jokes used in the study. The sustained anterior negativity to jokes was also observed in the present study. The effect was readily apparent in ERPs collected from right-handers, all of who scored very well on the comprehension questions that tested whether participants understood the jokes. But while the left-handers also scored extremely well on the comprehension questions, the sustained anterior negativity was either much reduced or entirely absent from their ERPs (see Figs. 1 and 3).

Cognitive processes indexed by this ERP effect might include the manipulation of information in working memory, and/or the suppression of joke-irrelevant information. For example, in the joke "By the time Mary had her fourteenth child, she'd run out of names to call her husband," the reader must reject the scenario where Mary chooses a name for her newborn baby, and infer instead that she is unhappy with her husband's fertility (via the activation of a painful-childbirth frame, or schema). Its left lateral focus is consistent with a generator in prefrontal cortex, an area that neuroimaging studies suggest is important for the manipulation of information in working memory [22]. Regions of prefrontal cortex are also known to be specialized for integrating diverse forms of information [62] and with solving problems that involve a number of interdependent elements [47], both aspects of the fluid interpretation needed for joke comprehension.

The absence of the sustained anterior negativity from left-handers' ERPs is perhaps the best evidence in the present study for more bilateral language representation in this group. In right-handers, the morphology of the waveform recorded from left anterior sites differs markedly from that recorded at counterpart electrodes over the RH (e.g., F7 vs. F8 in Fig. 1). In left-handers, waveforms recorded from left and right anterior sites are remarkably similar. This finding suggests neural processes associated with the highly asymmetric effect in right-handers' ERPs is subserved by different, and potentially more bilateral, processes in the left-handers. In fact, reduced joke effects at left anterior sites were accompanied by enhanced positive effects in the same time window and frequency range at frontal, central, and parietal electrode sites. These data suggest a trade-off between cognitive operations subserved by neural generators of the left anterior effect and the late positivity. As working memory operations are thought to be subserved by a network of brain areas including prefrontal, temporal, and parietal regions [11], we speculate that left-handers may rely more heavily on the temporal and parietal lobe contributions to working memory than do their right-handed counterparts. The empirical adequacy of this suggestion, however, would require study via functional neuroimaging.

\subsection{Functional consequences of lateral symmetry and asymmetry}

Differences observed in the present study are consistent with functional neuroimaging studies that reveal group differences in brain regions activated in high-level language comprehension tasks. In a PET study comparing story listening to rest, Tzourio et al. [71] found more symmetrical temporal lobe activations in left than right-handers, as well as more symmetrical deactivations in parietal and inferior frontal arreas. In a fMRI study comparing activation in the superior and middle temporal gyri during story listening 
(compared with listening to a reverse replay of the same story), activations were more bilateral in female than in male participants [41]. In contrast, brain areas activated by randomly ordered sentence fragments (compared to a reverse replay of the same materials) were similar in men and women [41]. Sex differences in lateralization have thus been argued to reflect narrative comprehension rather than phonological and syntactic aspects of language processing. Kansaku et al. suggest that the relatively large isthmus of the corpus callosum in females promotes more efficient interhemispheric communication in the posterior language regions that promotes bilateral processing of narrative structure.

Similarly, our finding in the present study that joke comprehension results in different ERP effects in left- and right-handers may reflect the high-level nature of the task. Indeed, most researchers have found no effect of handedness on ERPs to language materials $[2,65,66,72]$, though Kutas et al. [48] report more bilateral distribution of the N400 component in right-handers with left-handed relatives than in right-handers with no history of familial sinistrality. Although the jokes used here differed from the control stimuli in only a single word, understanding the jokes requires participants to retrieve information from long-term memory in order to reconstrue the scenario described in the initial part of the joke.

While putative differences in language lateralization did not affect behavioral indices of joke comprehension, accompanying ERP effects differed in left- and righthanded participants. Most notably, the highly asymmetric slow sustained negativity over left anterior electrode sites was present in right-handers' ERPs, but absent from lefthanders' ERPs to jokes. Jokes also elicited a late positivity in the same latency range as the slow sustained anterior negativity. The late positivity was larger in lefthanders' than right-handers' ERPs, and was more laterally symmetric in the left-handed women. These differences may reflect more efficient inter-hemispheric communication in the left-handers, as both left-handers and women are reputed to have relatively larger corpus callosal areas than right-handers and men, respectively. The observed attenuation of lateralized ERP effects in the left-handersespecially the left-handed women in our sample - suggest language lateralization is indeed relevant for joke comprehension and raises the question of exactly how differing degrees of cerebral asymmetry change the implementation of this high-level task.

\section{References}

[1] J.E. Alexander, J. Polich, Handedness and P300 from auditory stimuli, Brain and Cognition 35 (1997) 259-270.

[2] S.E. Barrett, M.D. Rugg, Asymmetries in event-related potentials during rhyme matching: confirmation of the null effect of handedness, Neuropsychologia 27 (1989) 539-548.

[3] L. Benton, R. Meyers, G.J. Polder, Some aspects of handedness, Psychiatric Neurology 144 (1962) 321-337.
[4] A. Bihrle, H. Brownell, H. Gardner, Comprehension of humorous and nonhumorous materials by left- and right-brain damaged patients, Brain and Cognition 5 (1986) 399-411.

[5] J.L. Bradshaw, N.C. Nettleton, The nature of hemispheric specialization in man, Behavioral and Brain Sciences 4 (1981) 51-91.

[6] P.A. Broca, Sur la faculte du language articule, Bulletin de la Societe Anatomie de Paris 6 (1865) 493-494.

[7] H. Brownell, D. Michel, J. Powelson, H. Gardner, Surprise but not coherence: sensitivity to verbal humor in right-hemisphere patients, Brain and Language 18 (1983) 20-27.

[8] H. Brownell, D. Michel, J. Powelson, H. Gardner, Inference deficits in right brain-damaged patients, Brain and Language 27 (1986) $310-321$

[9] M.P. Bryden, Perceptual asymmetry in vision: relation to handedness, eyedness, and speech lateralization, Cortex 9 (1973) 418-432.

[10] M.P. Bryden, Correlates of the dichotic right-ear effect, Cortex 24 (1988) 313-319.

[11] R.N. Cabeza, L. Nyberg, Neural bases of learning and memory: functional neuroimaging evidence, Current Opinion in Neurology 13 (2000) 415-421.

[12] D.J. Chwilla, C.M. Brown, P. Hagoort, The N400 as a function of the level of processing, Psychophysiology 32 (1995) 274-285.

[13] M. Coltheart, The MRC psycholinguistic database, Quarterly Journal of Experimental Psychology: A, Human Experimental Psychology 33 (1981) 497-505.

[14] S. Coulson, Semantic Leaps: Frame-Shifting and Conceptual Blending in Meaning Construction, Cambridge Univ. Press, Cambridge, UK, 2000.

[15] S. Coulson, C. van Petten, Conceptual integration and metaphor: an ERP study, Memory \& Cognition 30 (2002) 958-968.

[16] S. Coulson, M. Kutas, Getting it: human event-related brain response in good and poor comprehenders, Neuroscience Letters 316 (2001) $71-74$.

[17] S. Coulson, J.W. King, M. Kutas, ERPs and domain specificity: beating a straw horse, Language and Cognitive Processes 13 (1998) 653-672.

[18] S. Coulson, J.W. King, M. Kutas, Expect the unexpected: event-related brain response to morphosyntactic violations, Language and Cognitive Processes 13 (1998) 21-58.

[19] D.G. Daniel, M.S. Myslobodsky, L.J. Ingraham, R. Coppola, D.R. Weinberger, The relationship of occipital skull asymmetry to brain parenchymal measures in schizophrenia, Schizophrenia Research 2 (1989) $465-472$.

[20] H.L. Dee, Auditory asymmetry and strength of manual preference, Cortex 7 (1971) 236-245.

[21] P. Derks, L.S. Gillikan, D.S. Bartolome-Rull, E.H. Bogart, Laughter and electroencephalographic activity, Humor 10 (1997) 285-300.

[22] M. D'Esposito, Functional neuroimaging of working memory, in: R.K. Cabeza, A. Kingston (Eds.), Handbook of Functional Neuroimaging of Cognition, MIT Press, Cambridge, MA, 2000.

[23] N.R. Driessen, N. Raz, The influence of sex, age, and handedness of corpus callosum morphology: a meta-analysis, Psychobiology 23 (1995) 240-247.

[24] H. Gardner, P. Ling, L. Flamm, J. Silverman, Comprehension and appreciation of humour in brain-damaged patients, Brain 98 (1975) $399-412$

[25] K. Gloning, Handedness and aphasia, Neuropsychologia 15 (1977) $355-358$

[26] V. Goel, R.J. Dolan, The functional anatomy of humor: segregating cognitive and affective components, Nature Neuroscience 4 (2001) $237-238$

[27] T.C. Gunter, L.A. Stowe, G. Mulder, When syntax meets semantics, Psychophysiology 34 (1997) 660-676.

[28] C. Hardyck, A model of individual differences in hemispheric functioning, in: H.W.H.A. Whitaker (Ed.), Studies in Neurolinguistics, vol. 3, Academic Press, New York, 1977, pp. 223-256.

[29] H. Hecaen, J. Ajuriaguerra, Les Gauchers, Prevalence Manuelle et Dominance Cerebrale, Presses Universitaires de France, Paris, 1963. 
[30] H. Hecaen, J. Ajuriaguerra, Left-Handedness: Manual Superiority and Cerebral Dominance, Grune and Stratton, New York, 1964.

[31] H. Hecaen, S. Consoli, Analyse des troubles de language au cours del lesions de l'aire de Broca, Neuropsychologia 11 (1973) 377-388.

[32] H. Hecaen, J. Sauget, Cerebral dominance in left-handers, Cortex 7 (1971) 19-48.

[33] J. Hellige, Hemispheric asymmetry, Annual Review of Psychology 41 (1990) $55-80$.

[34] J. Hellige, M. Bloch, E. Cowin, T.L. Eng, Individual variation in hemispheric asymmetry: multitask study of effects related to handedness and sex, Journal of Experimental Psychology, General 123 (1994) 235-256.

[35] J.A. Higgenbottom, Relationships between sets of lateral and perceptual preference measures, Cortex 9 (1973) 402-409.

[36] D.S. Hines, P. Satz, Cross-modal asymmetries in perception related to asymmetry in cerebral function, Neuropsychologia 12 (1974) $239-247$

[37] L.D. Hoffman, J. Polich, P300, handedness, and corpus callosal size: gender, modality, and task, International Journal of Psychophysiology 31 (1999) 163-174.

[38] P. Holcomb, Automatic and attentional processing: an event-related brain potential analysis of semantic priming, Brain and Language 35 (1988) 66-85.

[39] H. Jasper, The ten twenty electrode system of the International Federation, Electroencephalography and Clinical Neurophysiology 10 (1958) 371-375.

[40] Y. Joanette, P. Goulet, D. Hannequin, Right Hemisphere and Verbal Communication, Springer-Verlag, New York, 1990.

[41] K. Kansaku, A. Yamaura, S. Kitazawa, Sex differences in lateralization revealed in the posterior language areas, Cerebral Cortex 10 (2000) 866-872.

[42] D. Kimura, Sex and Cognition, MIT Press, Cambridge, 1999.

[43] B. Knecht, B. Drager, M. Deppe, H. Lohmann, A. Floel, E.-B. Ringelstein, H. Henningsen, Handedness and hemispheric dominance in healthy humans, Brain 123 (2000) 2512-2518.

[44] S. Knecht, A. Floel, B. Drager, C. Breitenstein, J. Sommer, H. Henningsen, E.B. Ringelstein, A. Pascual-Leone, Degree of language lateralization determines susceptibility to unilateral brain lesions, Nature Neuroscience 5 (2002) 695-699.

[45] R.T. Knight, D. Scabini, D. Woods, C. Clayworth, Contributions of temporal-parietal junction to the human auditory P3, Brain Research 502 (1989) 109-116.

[46] A.W.B. Knox, D.R. Boone, Auditory laterality and tested handedness, Cortex 6 (1970) 164-173.

[47] J.K. Kroger, F.W. Sabb, C.L. Fales, S.Y. Bookheimer, M.S. Cohen, K.J. Holyoak, Recruitment of anterior dorsolateral prefrontal cortex in human reasoning: a parametric study of relational complexity, Cerebral Cortex 12 (2002) 477-485.

[48] M. Kutas, C. Van Petten, M. Besson, Event-related potential asymmetries during the reading of sentences, Electroencephalography and Clinical Neurophysiology 69 (1988) 218-233.

[49] D.A. Lake, M.P. Bryden, Handedness and sex differences in hemispheric asymmetry, Brain and Language 3 (1976) 266-282.

[50] J. Levy, A review of evidence for a genetic component in handedness, Behavior Genetics 6 (1976) 429-453.

[51] W.A. Lishman, E.R. McMeekan, Handedness in relation to direction and degree of cerebral dominance for language, Cortex 13 (1977) $30-43$.

[52] D. Loring, K.J. Meador, G.P. Lee, A.M. Murro, J.R. Smith, H.F. Flanigan, B.B. Gallagher, D.W. King, Cerebral language lateralization: evidence from intracarotid amobarbital testing, Neuropsychologia 28 (1990) 831-838.

[53] S. McDonald, Clinical insights into pragmatic theory: frontal lobe deficits and sarcasm, Brain and Language 68 (1996) 486-506.

[54] S. McDonald, Exploring the process of inference generation in sarcasm: a review of normal and clinical studies, Brain and Language 68 .
[55] J. McGlone, Sex differences in human brain organization: a critical survey, Behavioral and Brain Sciences 3 (1980) 215-227.

[56] W.F. McKeever, A.D. Van Deventer, Visual and auditory language processing asymmetries: influence of handedness, familial sinistrality, and sex, Cortex 13 (1986) 225-241.

[57] W.F. McKeever, A.D. Van Deventner, M. Suberi, Avowed, assessed, and familial handedness and differential hemispheric processing of brief sequential and non-sequential visual stimuli, Neuropsychologia 11 (1973) 235-238.

[58] W.F. McKeever, D.R. Nolan, J.A. Diehl, K.S. Seitz, Handedness and language laterality: discrimination of handedness groups on the dichotic consonant-vowel task, Cortex 20 (1984) 509-523.

[59] M. Nuwer, G. Comi, R. Emerson, A. Fuglsang-Frederiksen, J.-M. Guerit, H. Hinrichs, A. Ikeda, F.J.C. Luccas, P. Rappelsburger, IFCN standards for digital recording of clinical EEG, Electroencephalography and Clinical Neurophysiology 106 (1998) 259-261.

[60] R.C. Oldfield, The assessment and analysis of handedness: the Edinburgh inventory, Neuropsychologia 9 (1971) 97-113.

[61] D.L. Orsini, P. Satz, H.V. Soper, R.K. Light, The role of familial sinistrality in cerebral organization, Neuropsychologia 27 (1985) $223-232$.

[62] V. Prabhakaran, K. Narayan, Z. Zhao, J. Gabrieli, Integration of diverse information in working memory within the frontal lobe, Nature Neuroscience 3 (2000) 85-89.

[63] J. Pujol, J. Deus, J.M. Losilla, A. Capdevila, Cerebral lateralization of language in normal left-handed people studied by functional MRI, Neurology 52 (1999) 1038-1043.

[64] T. Rasmussen, B. Milner, The role of early left brain injury in determining lateralization of cerebral speech functions, Annals of the New York Academy of Sciences 299 (1977) 355-369.

[65] M.D. Rugg, The effects of handedness on event-related potentials in a rhyme-matching task, Neuropsychologia 27 (1985) 539-548.

[66] M.D. Rugg, S.E. Barrett, Event-related potentials and the interaction between orthographic and phonological information in a rhyme-judgment task, Brain and Language 32 (1987) 336-361.

[67] A. Searleman, Subject variables and cerebral organization for language, Cortex 16 (1980) 239-254.

[68] P. Shammi, D.T. Stuss, Humour appreciation: a role of the right frontal lobe, Brain 122 (1999) 657-666.

[69] S.P. Springer, G. Deutsch, Left Brain, Right Brain: Perspectives from Cognitive Neuroscience, 5th ed., Freeman/Times Books/Henry Holt and Co., New York, 1998

[70] J.P. Szaflarski, J.R. Binder, E.T. Possing, K.A. McKiernan, B.D. Ward, T.A. Hammeke, Language lateralization in left-handed and ambidextrous people: fMRI data, Neurology 59 (2002) 238-244.

[71] N. Tzourio, F. Crivello, B. Mellot, B. Nkanga-Ngila, B. Mazoyer, Functional anatomy of dominance for speech comprehension in left handers vs. right handers, NeuroImage 8 (1998) 1-16.

[72] J.W. Van Strien, R. Licht, A. Bouma, D.J. Bakker, Event-related potentials during word-reading and figure-matching in left-handed and right-handed males and females, Brain and Language 37 (1989) $525-547$.

[73] C. Wernicke, Der Aphasische Symptomenkomplex, Max Cohn Weigert, Breslau, 1874.

[74] E. Winner, H. Gardner, The comprehension of metaphor in braindamaged patients, Brain 100 (1977) 719-727.

[75] S.F. Witelson, Cognitive neuroanatomy: a new era, Neurology 42 (1992) 709-713.

[76] S. Yamaguchi, R.T. Knight, Anterior and posterior association cortex contributions to the somatosensory P300, Journal of Neuroscience 11 (1991) 2039-2054.

[77] S. Yamaguchi, R.T. Knight, Effects of temporal-parietal lesions on the somatosensory P3 to lower limb stimulation, Electroencephalography and Clinical Neurophysiology 84 (1992) 139-148.

[78] E.B.B. Zurif, M.P. Bryden, Familial handedness and left-right differences in auditory and visual perception, Neuropsychologia 7 (1969) $179-187$. 